\title{
Etiological Study of Corneal Blindness
}

\author{
Dr Mrs).Bhanu Devi, Prof., Head; Dr SumonKurmi,
}

Post Graduate Trainee, Department of Ophthalmology, Assam Medical College, Dibrugarh, Assam, India.

\begin{abstract}
:
Purpose - To study different etiology of corneal blindness and the distribution of corneal blindness according to age, sex, laterality, locality and socioeconomic status.

Methodology: All the patients with healed corneal pathology fulfilling the inclusion and exclusion criterias during the study period. Cases were also sub-grouped on the basis of sex, laterality of the involved eye locality and socioeconomic status.

Results: Out of 62 consecutive patients having corneal blindness male (66.13\%) and female (33.87\%); rural $(83.87 \%)$ and urban (16.13\%); unilateral (85.48\%) and bilateral (14.52\%); Upper lower socioeconomic group - 80.65\%, Upper lower socioeconomic group - 9.68\% and lower middle socioeconomic group - 9.68\%; Corneal blindness following - Post infection -42.25\%, Trauma - 21.19\%, Chemical injury - 8.85\%, Xerophthalmia - 8.45\%, Corneal Dystrophy - 2.81\%, Corneal Degeneration - $4.22 \%$ and Congenital - $7.04 \%$. Conclusions: The distribution of corneal blindness varies in different aspect like age, sex, occupation, socioeconomic status and locality.
\end{abstract}

Keyword: Assam, corneal blindness,

\section{Introduction}

Blindness is one of the major public health problem in the world. Blindness causes physical, social and economical dependence of a personon their family and society. Corneal Blindness is a visual morbidity that occurs when the transparency of cornea is affected so light cannot reach the light-sensitive retina of the eye and making a person blind. The epidemiology of corneal blindness is complicated and encompasses a wide variety of infectious and inflammatory eye diseases that cause corneals carring/opacity, which ultimately leads to functional blindness. According to the World Health Organization (WHO) Corneal blindness is the fourth leading cause of global blindness $(5.1 \%)$ after cataract, glaucoma and agerelated macular degeneration. ${ }^{1}$ Corneal blindness is a leading cause of blindness in developing countries. ${ }^{2}$ Worldwide, major investments in public health infrastructure and primary eye care services have built a strong foundation for treating and preventing future corneal blindness. ${ }^{3}$ Rapid Survey on Avoidable Blindness conducted under NPCB during 2006-07 showed reduction in the prevalence of blindness from 1.1\% (2001-02) to 1\% (2006-07). Various activities/initiatives undertaken during the Five Year Plans under NPCB are targeted towards achieving the goal of reducing the prevalence of blindness to $0.3 \%$ by the year 2020. As per NPCB the prevalence of corneal blindness in India is $0.90 \%$. ${ }^{4}$ According to the National Programme for Control of Blindness (NPCB) estimates, there are currently 120,000 corneal blind persons in the country and it is estimated that addition of 25,00030,000 corneal blindness cases every year in the country. ${ }^{5}$

\section{Materials And Methods}

Aims and objectives-

- $\quad$ To study the different aetiology of corneal blindness.

- To study the distribution of corneal blindness according to age, sex, laterality of the involved eye and socioeconomic status.

Place of study : Department of Ophthalmology; Assam Medical College \& Hospital; Dibrugarh

Duration of study: One year, $1^{\text {st }}$ July2015 to $30^{\text {th }}$ June 2016

Type of study : A hospital-based observational study.

SAMPLE SIZE: All the cases of corneal blindness attending at the Department of Ophthalmology; Assam Medical College \& Hospital; Dibrugarh during the study period fulfilling the inclusion and exclusion criteria's. Inclusion Criteria:

$\square$ Diminution of vision due to corneal cause

Agegroup : 5years and above

V Vision $\quad: \quad \leq 3 / 60$ (Snellen'schart) to Perception of Light+ve 


\section{ExclusionCriteria:}

L Loss of vision due to other ocular diseases associated with corneal cause

Vision: $>3 / 60$ (Snellen'schart) and Perception of light -ve cases

Ageless than 5 years

\section{Ethical clearance}

Prior to the commencement of study ethical clearance was obtained from the Ethics committee of Assam Medical College \& Hospital, Dibrugarh. All the patients attending with healed corneal pathology fulfilling the inclusion and exclusion criterias during the study period. The diagnosis was based on the medical history and the clinical examination and in some cases special investigations whenever necessary. The best corrected visual acuity was recorded as per Snellen's chart. All the cases with healed corneal pathology with visual acuity $\leq 3 / 60$ (as per Snellen's chart) to Perception of light (PL+) irrespective of visual acuity of the other eye were included in this study. Special investigations such as tonometry, keratometry, ultrasonography examination performed whenever necessary. Cases were also sub-grouped on the basis of sex, laterality of the involved eye, locality and Socioeconomic status to see the distribution of corneal blindness. The data and results were tabulated and statistically analysed in software Microsoft Excel 2010. Qualitative data was described as number (percentage \%) and quantitative data has been described as Mean \pm SD and Median (range) as appropriate.

\section{Result And Observation}

The present study based on 62 cases of Corneal blindness attending at the department of Assam Medical College, Dibrugarh, during a period from $1^{\text {st }}$ July 2015 to $30^{\text {th }}$ June 2016 from $1^{\text {st }}$ July 2015 to $30^{\text {th }}$ June 2016.

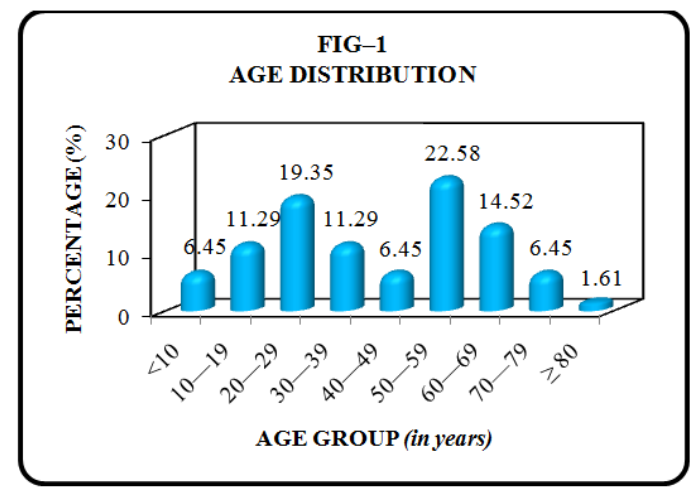

Fig-1. Distribution of corneal blindness according to age

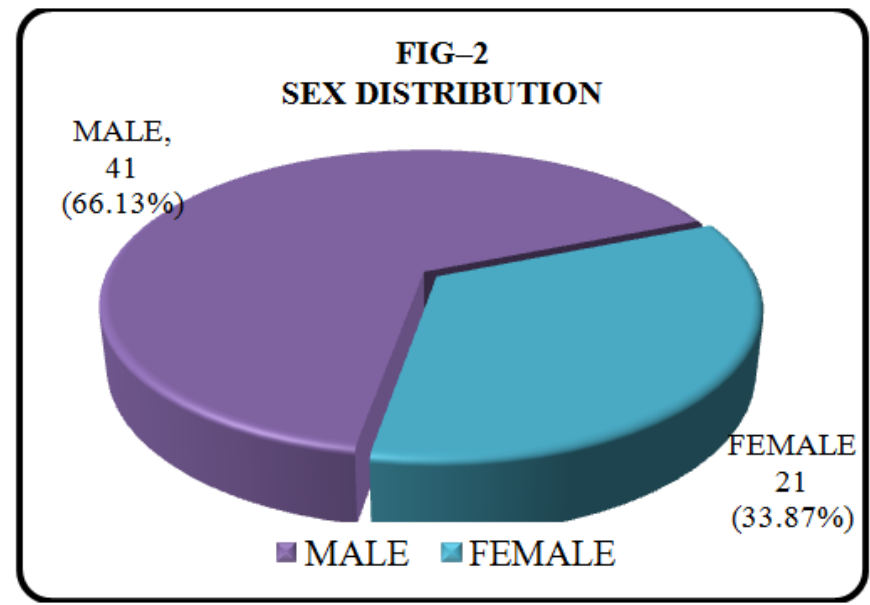

Fig.2- Distribution of corneal blindness according to sex 


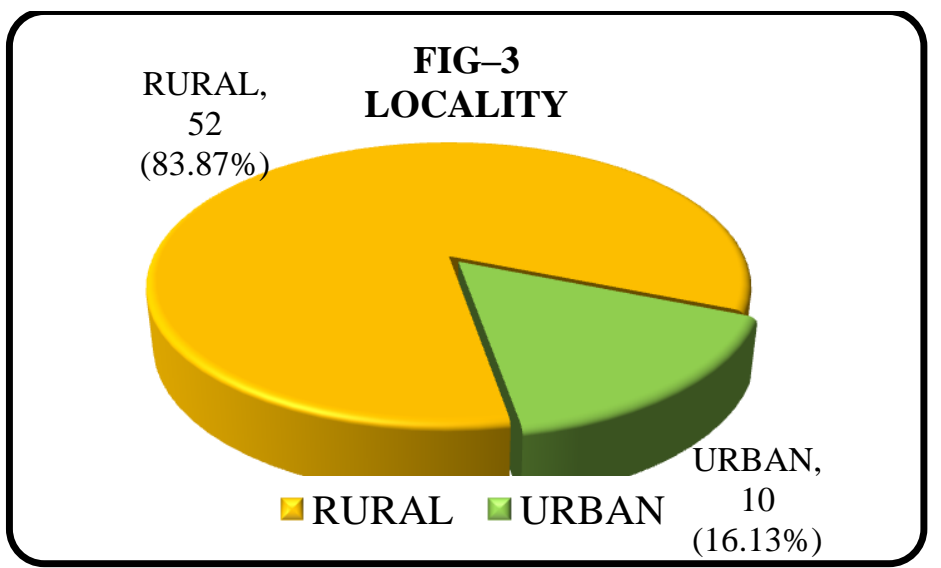

Fig.3- Distribution of corneal blindness according to locality

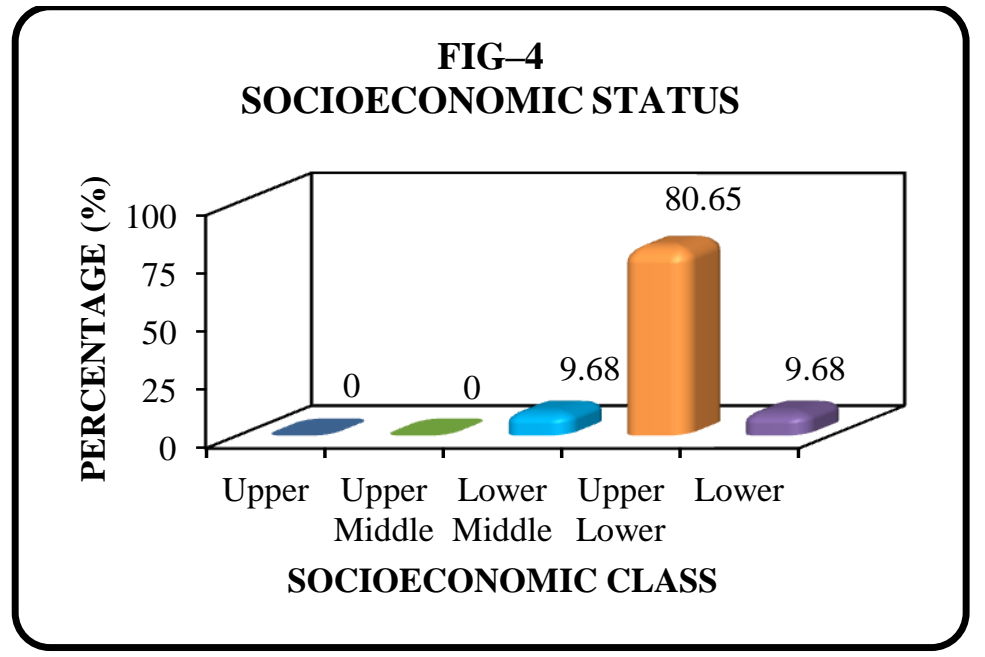

Fig.4 - Distribution of corneal blindness according to Socioeconomic Status (Kuppuswamy's Socioeconomic Status scale 2014)

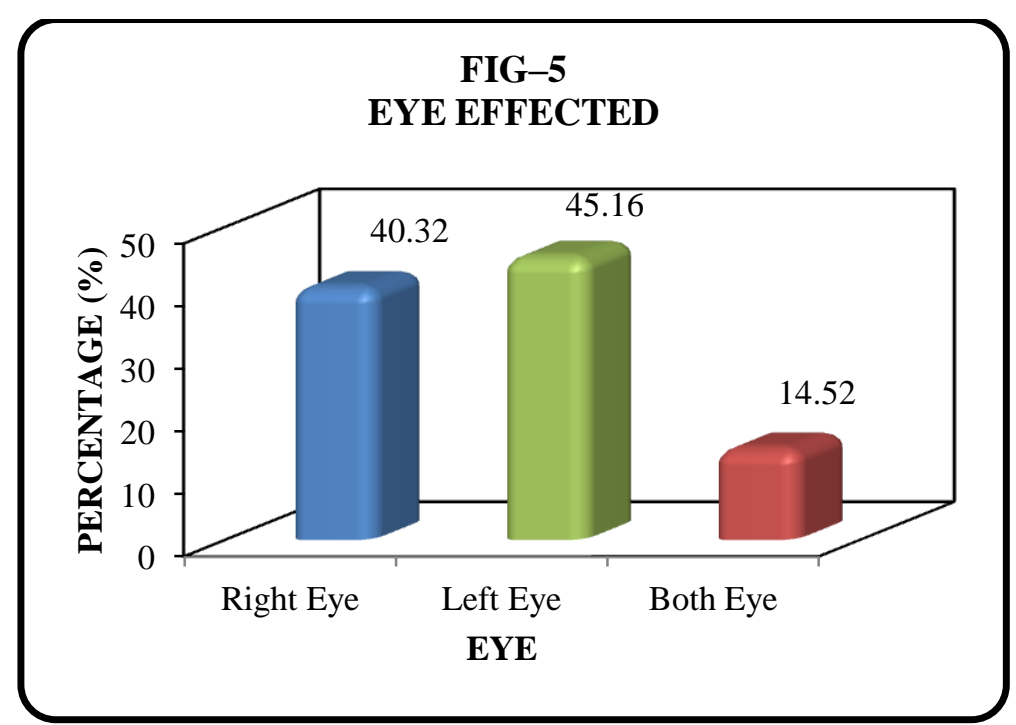

Fig.5- Distribution of corneal blindness according to laterality 
FIG-6

VISUAL ACUITY

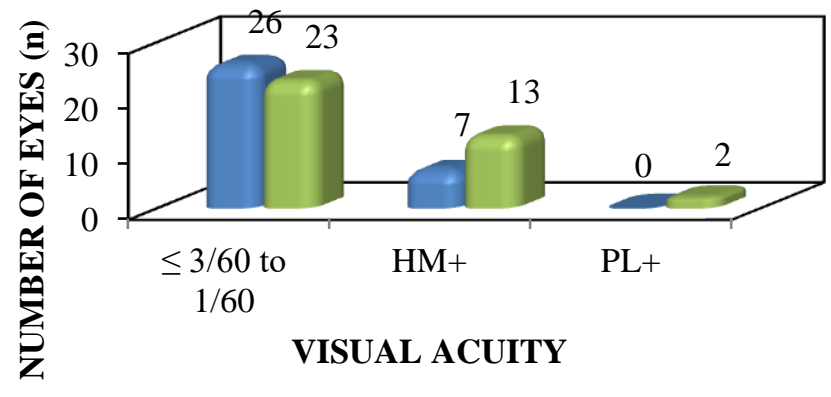

口RIGHT $\square$ LEFT

Fig.6- Distribution of corneal blindness according to visual acuity

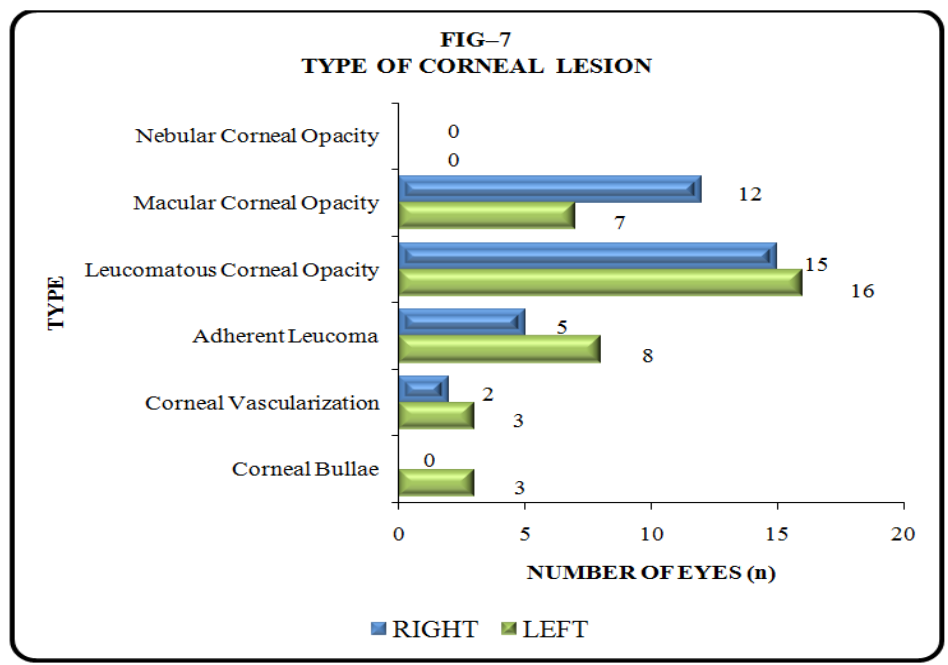

Fig.7- Distribution of corneal blindness according to corneal lesion

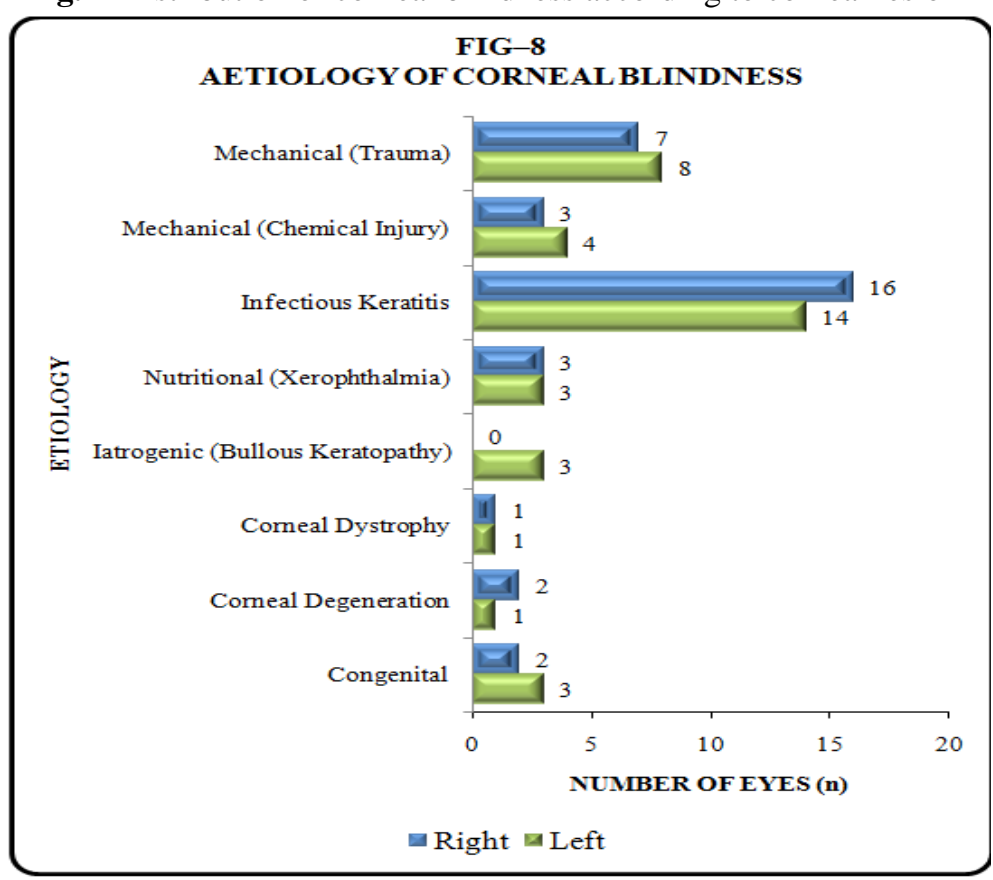

Fig. 8- distribution of corneal blindness according to etiology 


\section{Discussion}

Majority of the cases corneal blindness are unilateral. ${ }^{7}$ NPCB-WHO (National Programme for Control of Blindness-World Health Organization) was estimated 5.96 lakh unilateral blindand 1.91 lakhs bilateral blind. ${ }^{8}$ In the present study unilateral corneal blindness was $85.48 \%$ and bilateral $14.52 \%$. Trauma is the most important predisposing factor of unilateral corneal blindness in developing countries. Xerophthalmia, corneal dystrophy, congenital causes showed bilateral involvement of corneal.

\begin{tabular}{|c|c|c|c|c|}
\hline SI. No. & Authors & Year & Unilateral (\%) & Bilateral (\%) \\
\hline 1 & NPCB-WHO report & 1986 & 80.33 & 65 \\
\hline 2 & Attis S. et al & 2015 & 80.9 & 35 \\
\hline 3 & Nikose A. et al & 2013 & 85.48 & 19.04 \\
\hline 4 & Present Study & $2015-2016$ & & 14.52 \\
\hline
\end{tabular}

The present study showed corneal blindness was higher among male. The sex distribution was $66.13 \%$ male and $33.87 \%$ female. Most of the male were farmer and tea garden worker so presumably higher risk of corneal injury during their work. Males form the majority of working class, hence exposure to risk factors is more. Moreover, male are usually in the outdoor work so they may give less importance on medication and lack of ocular hygiene after corneal injury or any corneal pathology.

\begin{tabular}{|c|c|c|c|c|}
\hline Sl. No. & Authors & Year & Male (\%) & Female (\%) \\
\hline 1 & Attis S et al & 2015 & 67 & 33 \\
\hline 2 & Nikose A et & 2015 & 52.4 & 47.6 \\
\hline 3 & Present study & $2015-2016$ & 66.13 & 33.87 \\
\hline
\end{tabular}

In our study showed majority of corneal blindness cases were from rural areas. Out of 62 cases of corneal blindness $52(83.87 \%)$ cases belonged to rural areas and $10(16.13 \%)$ were urban population. It is higher than the previous study as Assam Medical College \& Hospital, Dibrugarh is surrounded with rural areas. The distribution of corneal blindness is more in rural population and most of them had agricultural background. The rural people may expose more to injury during their work. K. R avinderet al, AttisS. et al, Wagenet al ${ }^{9}$ found in rural population were associated with an increased prevalence of corneal blindness Moreover, it may be due to lack of availability of health care facility and awareness regarding corneal injury and corneal infective conditions. Most of patient had delay in consulting ophthalmologist and some patients used native modalities of treatment like application of some irritants in eye and removal of foreign body with un sterile material prior to medical treatment. Moreover, it may be lack of ocular hygiene, poverty, lack of health care facility and Ophthalmologist in the rural area. Cultivation and tea garden work (under tea garden industry) is the major occupation in this district. They have more prone to ocular trauma.

Dandonaet al conducted a study 2001 and he found corneal blindness due to keratit is (22.2\%), trauma (23.2\%), iatrogenic (5.0\%), spheroidal degeneration (4\%), traditional eye medicine (4.0\%). ${ }^{10}$

Tandonet al conducted a hospital-based study at NewDelhi, 2010 showed 59 diagnosed cases of corneal blindness with distribution of corneal infection (62.5\%), Chemical injury (5.7\%), corneal dystrophy (7.1\%), Keratomalacia (5.4\%), Bullous Keratopathy (8.9\%), and Corneal degeneration (3.6\%). ${ }^{11}$

Attis S. et al study showed corneal blindness caused by trauma (37\%), infection (33\%), congenital and developmental cause (15\%) and degeneration and dystrophy $(15 \%) .^{12}$

VeladanaR.et alfound trauma (59.3\%), infectious keratitis (23.2\%), corneal degenerations (12\%) and postsurgical bull ous kerato pathy (5.5\%) are responsible for the major burden of corneal blindness. ${ }^{13}$ Malnutrition due to vitamin A deficiency is also an important factor of childhood corneal blindness. In the present study corneal blindness due to xerophthalmia was $8.54 \%$ which was bilateral blindness. Sachdevaet al conducted a study in 2011 where prevalence of xerophthalmia was $9.1 \% .{ }^{14}$ In the present study Corneal blindness because of Congenital, corneal dystrophy and corneal degeneration were seen bilaterally and involved $7.04 \%, 2.81 \%$ and $4.22 \%$ respectively which is almost similar with different studies. From the present study it was evident that numbers of an etiology were responsible for corneal blindness. High percentage rate of corneal blindness was seen following trauma. Most of them associated with agricultural work and tea-plantation. In the study population injured their eye by paddy leaves, tea leaves, tail of animal, bamboo stick, stationary items or glass. When there is break in normal corneal tissue it increases the susceptibility of secondary infection. Sometimes corneal tissue heals after trauma and leaving a corneal scar/opacity without under going secondary infection. Most of the corneal opacity was seen following infective keratitis (either bacterial or fungal) which pre disposed by trauma. In all the corneal opacity following fungal in fection was pre-existing ocular trauma. 
Etiological Study Of Corneal Blindness

\begin{tabular}{|c|c|c|c|c|c|}
\hline Aetiology & $\begin{array}{r}\text { Dandonaet } \\
\text { al2001 }\end{array}$ & $\begin{array}{l}\text { Tandon et } \\
\text { al2010 }\end{array}$ & AttiS et al 2015 & $\begin{array}{c}\text { Veladana R.et al } \\
2016\end{array}$ & $\begin{array}{c}\text { Present Study } \\
2015-16\end{array}$ \\
\hline Trauma & $23.2 \%$ & & $37 \%$ & $59.3 \%$ & $21.19 \%$ \\
\hline Lime burn & & $5.7 \%$ & & & $9.85 \%$ \\
\hline Post infection & $22.2 \%$ & $62.5 \%$ & $33 \%$ & $23.2 \%$ & $42.25 \%$ \\
\hline $\begin{array}{l}\text { Pseudophakic Bullous } \\
\text { keratopathy }\end{array}$ & $5.0 \%$ & $8.9 \%$ & & $5.5 \%$ & $4.22 \%$ \\
\hline Xerophthalmia & & $5.4 \%$ & & & $8.54 \%$ \\
\hline Corneal dystrophy & & $7.1 \%$ & \multirow[t]{2}{*}{$15 \%$} & & $2.81 \%$ \\
\hline Corneal degeneration & $4 \%$ & $3.6 \%$ & & $12 \%$ & $4.22 \%$ \\
\hline Congenital & & & & & $7.04 \%$ \\
\hline
\end{tabular}

\section{Conclusion}

In the present study it was found that distribution of corneal blindness varies in different aspect like age, sex, laterality, occupation, socioeconomic status and locality. Unilateral corneal blindness is more common than bilateral corneal blindness. Numbers of corneal blindness in male is higher than female. Moreover, the distribution of corneal blindness was higher with increasing age, illiteracy, decreasing socioeconomic status and among the rural populations with an agricultural background. Post-traumatic and post-infectious corneal opacities/scars are the common cause of corneal blindness. Ocular trauma is a common cause of corneal blindness and is known to be the most common cause of unilateral loss of vision which can be prevented by the avoidance of risk factors. Corneal blindness following Xerophthalmia due to vitamin A deficiency is also another identified preventable blindness. Corneal blindness one of the major problem in the field of preventive and community Ophthalmology and is a great challenge to the Ophthalmologist.

\section{Bibliography}

[1]. Prevention of blindness and visual impairment. [Last accessed on 2014 December 30]. Available from: http://www.who.int/blindness/ causes/en.

[2]. Garg P, Krishna PV, Stratis AK, Gopinathan U. The value of corneal transplantation in reducing blindness. Eye (Lond) 2005;19:1106-14.

[3]. Matthew S Oliva. Tim Schottman, Manoj Gulati. Turning the tide of corneal blindness - Indian J Ophthalmol 2012;60:423-

[4]. http://npcb.nic.in/writereaddata/mainlinkfile/File285.pdf

[5]. National Programme for Control of Blindness. [Last accessed on 2011 October 30]. Available from:http://pbhealth.gov.in/pdf/ Blindness.pdf.

[6]. Kuppuswamy's Socio-Economic Status Scale - A Revision of Income Parameter For 2014. International Journal of Recent Trends in Science And Technology. 2014;,, Volume 11,(Issue 1, 2014 pp 01-02):ISSN 2277-2812 E-ISSN 2249-8109.

[7]. Tandon R, Sinha R, Moulick P, Agarwal P, Titiyal JS, Vajpayee RB. Pattern of bilateral blinding corneal disease in patients waiting for keratoplasty in a tertiary eye care centre in northern India. Cornea. 2010;29:269-71

[8]. Saini JS, Reddy MK, Jain AK, Ravindra MS, Jhaveria S, Raghuram L. Perspectives in eye banking. Indian J Ophthalmol. 1996;44:47-55

[9]. Wang H, Zhang Y, Li Z, Wang T, Prevalense and causes of corneal blindness. Clin Experiment Ophthalmol, 2014 Apr, 42(3):24953

[10]. Dandona R. Corneal blindness in a southern Indian population: need for health promotion strategies. British Journal of Ophthalmology. 2003; 87(2):133-141.

[11]. Tandon R, Sinha R, Moulick P, Agarwal P, Titiyal JS, Vajpayee RB, Pattern of bilateral blinding corneal disease in patients waiting for keratoplasty in a tertiary eye care centre in North India. Cornea 2010, 29:269-71

[12]. Atti s. a clinical study of etiology of corneal opacities. telengana: mrims journal of health science; 2015

[13]. Veladanda R. A Hospital Based Clinical Study on Corneal Blindness in a Tertiary Eye Care Centre in North Telangana. Karimnaga: Journal of Krishna Institute of Medical Sciences University; 2016.

[14]. Sachdeva S, Alam S, Beig F, Khan Z, Khalique N. Determinants of vitamin A deficiency amongst children in Aligarh District, Uttar Pradesh. Indian Pediatr 2011;48:861-6. 